Results: 92 primary care practices were randomized, 679 patients participated (64\% women, mean age 36.2 years (SD7.5) and median CLBP duration 9 years (IQR 4-15 years). 333 patients were randomized to the intervention group, both groups had similar characteristics at baseline. Sixty percent of participants had a positive referral rule. RMDQ scores are shown in table 1. Sub scores are shown for patients with a positive outcome of the referral rule (PRR) and a negative outcome of the referral rule (NRR). The change in RMDQ score after 4 months in the intervention group was -0.74 ( $95 \%$ confidence interval $(\mathrm{Cl})-1.31--0.18)$ and in the control group $-0.46(95 \% \mathrm{Cl}-0.98-0.05)$. There was no significant difference between groups.

\begin{tabular}{|c|c|c|}
\hline & RMDQ at baseline & RMDQ after 4 months \\
\hline Use of referral rule, mean ( $95 \% \mathrm{Cl}$ ) & $8.38(7.58-9.18)$ & $7.64(6.78-8.49)$ \\
\hline PRR^, mean $(95 \% \mathrm{Cl})$ & $8.51(7.56-9.45)$ & $7.77(6.74-8.79)$ \\
\hline$N R R \pm$, mean $(95 \% \mathrm{Cl})$ & $8.19(7.02-9.35)$ & $7.44(6.18-8.69)$ \\
\hline Usual care, mean $(95 \% \mathrm{Cl})$ & $8.61(7.82-9.39)$ & $8.14(7.33-8.96)$ \\
\hline $\mathrm{PRR}^{\wedge}$, mean $(95 \% \mathrm{Cl})$ & $8.58(7.65-9.50)$ & $7.83(6.87-8.79)$ \\
\hline NRR \pm , mean $(95 \% \mathrm{Cl})$ & $8.65(7.55-9.76)$ & $8.74(7.54-9.93)$ \\
\hline
\end{tabular}

Conclusions: Compared with usual care, use of the $\mathrm{CaFaSpA}$ referral rule in CLBP patients in a primary care setting did not significantly impact disability in these patients, 4 months after a referral advice was made. Results after 12 and 24 months should be awaited before definitive conclusions about the impact of the $\mathrm{CaFaSpA}$ referral rule for axSpA in CLBP patients can be made.

Disclosure of Interest: None declared

DOI: 10.1136/annrheumdis-2017-eular.6041

\section{AB0723 TECHNICAL AIDS AGREED AMONG SPECIALISTS FOR THE MANAGEMENT OF COMORBIDITY IN PATIENTS WITH AXIAL SPONDYLOARTHRITIS: THE GECOAX PROJECT}

C. González ${ }^{1}$, R. Curbelo ${ }^{2}$, J.C. Torre-Alonso ${ }^{3}$, E. Collantes ${ }^{4}$, S. Castañeda ${ }^{5}$, M.V. Hernández ${ }^{6}$, A. Urruticoechea-Arana ${ }^{7}$, J.C. Nieto ${ }^{1}$, J. García $^{8}$, M.Á. Abad $^{9}$, J. Ramírez ${ }^{6}$, C. Suárez ${ }^{10}$, R. Dalmau ${ }^{11}$, M.D. Martín-Arranz ${ }^{12}$, L. León ${ }^{13}$, J.C. Hermosa ${ }^{14}$, J.C. Obaya ${ }^{15}$, T. Otón ${ }^{2}$, L. Carmona ${ }^{2}$.

${ }^{1}$ Rheumatology, HU Gregorio Marañón; ${ }^{2}$ InMusc, Madrid; ${ }^{3}$ Rheumatology, HU Monte Naranco, Oviedo: ${ }^{4}$ Rheumatology, HU Reina Sofía, Córdoba:

${ }^{5}$ Rheumatology, HU la Princesa, IIS-IP, Madrid; ${ }^{6}$ Rheumatology, HU Clinic $i$

Provincial, Barcelona; ${ }^{7}$ Rheumatology, $\mathrm{H}$ Can Misses, Ibiza; ${ }^{8}$ Rheumatology, $\mathrm{HU}$ 12 de Octubre, Madrid; ${ }^{9}$ Rheumatology, $\mathrm{H}$ de Plasencia, Plasencia; ${ }^{10}$ Internal Medicine, HU la Princesa, IIS-IP; ${ }^{11}$ Cardiology; ${ }^{12}$ Gastroenterology, HU la Paz; ${ }^{13}$ Psychology, UCJC, Madrid; ${ }^{14}$ Centro de Salud Ciudades, Getafe; ${ }^{15}$ Centro de Salud Alcobendas, Alcobendas, Spain

Background: The management of comorbidity in patients with axial spondyloarthritis $(A x-S p A)$ needs improvement; the implementation of clinical practice guidelines is still deficient and heterogeneous.

Objectives: To prioritise comorbidities in $\mathrm{Ax}-\mathrm{SpA}$ and to elaborate practical aids for their identification and follow-up.

Methods: A multidisciplinary panel [10 rheumatologists ( 6 experts in Ax-SpA), 2 family doctors, 1 internist, 1 cardiologist, 1 gastroenterologist, 1 psychologist and 3 methodologists] prioritised, in a discussion group, a list of comorbidities based on frequency and impact. Each comorbidity was discussed largely and systematic reviews were performed to support or discard items. In a second meeting, items to be included were presented, discussed, and those with lower priority disregarded. Results: The panel produced a checklist for health professionals and another for patients. Each item is supported by arguments and references. Table 1 shows, schematically, the items included in the checklists.

Table 1. Items included in the checklist

\begin{tabular}{ll}
\hline Usual treatment & $\begin{array}{l}\text { Of note: oral anticoagulants, antihypertensive drugs, } \\
\text { ASA, steroids and NSAIDs. }\end{array}$ \\
\hline Specific comorbidities & $\begin{array}{l}\text { Hypertension, heart failure, renal failure, liver cirrhosis, } \\
\text { gastric ulcer, infections, tuberculosis, neurological } \\
\text { disease, and fracture risk. }\end{array}$ \\
Vaccine schedule and dental hygiene & $\begin{array}{l}\text { Patient's vaccination status; prevention of infections. } \\
\text { Physical activity (amount and type). }\end{array}$ \\
Life-style & $\begin{array}{l}\text { Alcohol consumption. Detect possible abuses; } \\
\text { important risk factor for other comorbidities. }\end{array}$ \\
Depression, quality of sleep and & $\begin{array}{l}\text { The impact of Ax-SpA in the psychosocial sphere is } \\
\text { relevant and should be carefully evaluated. Specific } \\
\text { sexual life }\end{array}$ \\
questionnaires are recommended. \\
Non-preventable diseases & $\begin{array}{l}\text { Frequent association with uveitis, inflammatory bowel } \\
\text { disease and cardiac pathology; systematise questions }\end{array}$ \\
\hline
\end{tabular}

Conclusions: These checklists are intended to facilitate the systematic evaluation of co-morbidity associated with Ax-SpA, thus allowing an earlier detection and better control and management of these patients by the rheumatologist.
Acknowledgements: This project was funded by Merck Sharp \& Dohme Spain. Merck Sharp \& Dohme had no influence on either the development of the project or the final content of the abstract.

Disclosure of Interest: None declared

DOI: 10.1136/annrheumdis-2017-eular.4795

\section{AB0724 HIGHER LIKELIHOOD OF ANTI-TNF PRESCRIPTION IN MEN VS WOMEN WITH ANKYLOSING SPONDYLITIS DESPITE SIMILAR DISEASE BURDEN: RESULTS FROM ROUTINE CARE AT TWO ACADEMIC RHEUMATOLOGY CENTERS OF USA AND SPAIN}

M. Blasco-Blasco $^{1}$, I. Castrejón ${ }^{2}$, M. Ruiz-Cantero ${ }^{1}$, V. Jovaní ${ }^{3}$, E. Pascual ${ }^{4}$ J. Block ${ }^{2}$, T. Pincus ${ }^{2} .{ }^{1}$ Public Health, University of Alicante, Alicante, Spain;

${ }^{2}$ Rheumatology, Rush University Medical Center, Chicago, United States;

${ }^{3}$ Rheumatology, Alicante University General Hospital; ${ }^{4}$ Rheumatology, Miguel Hernandez University, Alicante, Spain

Background: Ankylosing spondylitis (AS) has been considered to be more prevalent in men compared to women. Besides, the clinical presentation in women is thought to be milder and more peripheral than in men. Some studies have suggested a higher burden of disease in women ${ }^{1,2}$ but others not confirm these differences ${ }^{3,4}$

Objectives: To evaluate possible gender differences in men and women with AS seen in routine care at two academic rheumatology centers of the USA and Spain.

Methods: Sixty one men and 30 women with AS in Spain and 61 men and 31 women in the USA completed a Multidimensional Health Assessment Questionnaire (MDHAQ). The MDHAQ includes (0-10 scores) for physical function, pain, patient global estimate (PATGL), compiled into a 0-30 RAPID3, and fatigue scores. Furthermore, demographic data, biological (anti-TNF $\alpha$ ) and DMARD therapies, were obtained from the medical records. A comparative analysis of men and women was performed by Mann-Whitney $\mathrm{U}$ tests for nonparametric quantitative data (median/interquartile range), and Chi square tests for qualitative data (frequencies/percentajes).

Results: We have not detected significant differences in men and women for function, pain, PATGL, or fatigue although a trend towards higher RAPID3 values was seen in females in both sites (Table). Anti-TNF $\alpha$ medications were prescribed more often in men than in women $(81.2 \%$ vs $65.6 \%$, in all patients $\mathrm{p}=0.02)$, statistically significant in Spain ( $82 \%$ vs $60 \%, p=0.02)$, and numerically higher in the USA $(80.3 \%$ vs $71 \%, p=0.31)$. DMARD medications tend to be more prescribed in women than men in all patients $(17.2 \%$ vs $23 \%, p=0.35)$ although no statistically significant.

Table 1. Health status and treatment of patients with $\mathrm{SpA}$ at two academic centers $\left({ }^{*} \mathrm{p}<0.05\right)$

\begin{tabular}{lccccc}
\hline & \multicolumn{2}{c}{ USA } & & \multicolumn{2}{c}{ Spain } \\
\cline { 2 - 3 } \cline { 5 - 6 } & Men (N=61) & Women $(\mathrm{N}=31)$ & & Men $(\mathrm{N}=61)$ & Women $(\mathrm{N}=30)$ \\
\hline Age, years & $41.5(31.7-56.9)$ & $36.2(31.7-56.8)$ & $52.0(46.0-65.4)$ & $54.6(43.3-61.4)$ \\
Education, years & $16(12-17)$ & $16(11-18)$ & & $9(8-12)$ & $8(8-12)$ \\
White & $31(51 \%)$ & $17(55 \%)$ & & $56(92 \%)$ & $30(100 \%)$ \\
Duration disease, years & $12.1(6.1-21.5)$ & $6.3(4-16.6)$ & & $22(12.1-34.8)$ & $21.4(12.1-30.1)$ \\
HLA-B27+ & $26(68 \%)$ & $21(88 \%)$ & & $49(86 \%)$ & $20(69 \%)$ \\
MDHAQ & & & & & \\
$\quad$ Function, (0-10) & $2(0.3-4)$ & $2.3(0.3-4)$ & & $1.2(0-2.7)$ & $0.8(0-2.3)$ \\
$\quad$ Pain, (0-10) & $4(1-7)$ & $5(2-7.5)$ & & $3(1.5-6)$ & $4(1-5)$ \\
$\quad$ PATGL, $(0-10)$ & $3(1.5-6.3)$ & $5(2-6.5)$ & & $4(2-5.5)$ & $3.5(1-5.5)$ \\
$\quad$ RAPID3, (0-30) & $8.5(4.2-15.3)$ & $11.8(4-16.8)$ & $6.8(3.5-14.2)$ & $8.1(3.3-12.7)$ \\
$\quad$ Fatigue, (0-10) & $3(0-6.5)$ & $5(3-8)$ & & $3(1-4.5)$ & $2.8(1-5.5)$ \\
Treatment & & & & & \\
$\quad$ Anti-TNF $\alpha$ & $49(80 \%)$ & $22(71 \%)$ & & $50(82 \%)$ & $18(60 \%)^{\star}$ \\
$\quad$ DMARD & $9(15 \%)$ & $7(23 \%)$ & $13(21 \%)$ & $7(23 \%)$ \\
\hline
\end{tabular}

Conclusions: Men with SpA receive anti-TNF $\alpha$ more likely than women; although disease burden appears somewhat higher in women. This pattern is similar in both Spain and the USA, though statistically significant only in the Spanish population. Other parameters may be having weight in the management of $\mathrm{SpA}$, such as radiographic signs versus peripheral manifestations.

References:

[1] van der Horst-Bruinsma IE, et al. Ann Rheum Dis 2013.

[2] Ortega Castro R, et al. Reumatol Clin 2013.

[3] Gremese E, et al. Rheumatology (Oxford) 2014.

[4] Shahlaee A, et al. Clin Rheumatol 2015.

Acknowledgements: University Institute for Gender Studies (University of Alicante) supported MBB.

Disclosure of Interest: M. Blasco-Blasco: None declared, I. Castrejón: None declared, M. Ruiz-Cantero: None declared, V. Jovaní: None declared, E. Pascual: None declared, J. Block: None declared, T. Pincus Shareholder of: Health Report Services, Inc.

DOI: 10.1136/annrheumdis-2017-eular.3525 